\title{
Correction to: Effects of nicomethanol hydrofluoride on dental enamel and synthetic apatites: a role for anti-caries protection
}

\section{N. Sharkov ${ }^{1}$ (1)}

Published online: 28 November 2017

c) European Academy of Paediatric Dentistry 2017

\section{Correction to: Eur Arch Paediatr Dent https://doi.org/10.1007/s40368-017-0314-8}

The author of the article "Effects of nicomethanol hydrofluoride on dental enamel and synthetic apatites: a role for anti-caries protection", N. Sharkov, requested open access publication but owing to an error by the publisher the article was published electronically on the publisher's internet portal (currently SpringerLink) on 4 November 2017 without open access.
The original article can be found online at https://doi.org/10.1007/ s40368-017-0314-8.

\section{N. Sharkov}

sharkov@omega.bg

1 Department of Paediatric Dental Medicine, Faculty of Dental Medicine, Medical University, Sofia, Bulgaria
The copyright of the article has been changed to $($ ) The Author(s) 2017 and the article is forthwith distributed under the terms of the Creative Commons Attribution 4.0 International License (http://creativecommons.org/licenses/ by/4.0/), which permits use, duplication, adaptation, distribution and reproduction in any medium or format, as long as appropriate credit is given to the original author(s) and the source, a link is provided to the Creative Commons license, and any changes made are indicated. 